\title{
Optimal locations of sea-level indicators in glacial isostatic adjustment investigations
}

\author{
H. Steffen ${ }^{1}$, P. Wu ${ }^{2,3}$, and H. Wang ${ }^{4}$ \\ ${ }^{1}$ Lantmäteriet, Lantmäterigatan 2c, 80182 Gävle, Sweden \\ ${ }^{2}$ Department of Geoscience, University of Calgary, 2500 University Drive NW, Calgary, AB, T2N 1N4, Canada \\ ${ }^{3}$ now at: Department of Earth Sciences, The University of Hong Kong, Pokfulam Road, Hong Kong \\ ${ }^{4}$ State Key Laboratory of Geodesy and Earth's Dynamics, Institute of Geodesy and Geophysics, Chinese Academy of \\ Sciences, Wuhan 430077, China
}

Correspondence to: H. Steffen (holger-soren.steffen@1m.se)

Received: 19 November 2013 - Published in Solid Earth Discuss.: 18 December 2013

Revised: 14 March 2014 - Accepted: 29 April 2014 - Published: 19 June 2014

\begin{abstract}
Fréchet (sensitivity) kernels are an important tool in glacial isostatic adjustment (GIA) investigations to understand lithospheric thickness, mantle viscosity and ice-load model variations. These parameters influence the interpretation of geologic, geophysical and geodetic data, which contribute to our understanding of global change.

We discuss global sensitivities of relative sea-level (RSL) data of the last 18000 years. This also includes indicative RSL-like data (e.g., lake levels) on the continents far off the coasts. We present detailed sensitivity maps for four parameters important in GIA investigations (ice-load history, lithospheric thickness, background viscosity, lateral viscosity variations) for up to nine dedicated times. Assuming an accuracy of $2 \mathrm{~m}$ of RSL data of all ages (based on analysis of currently available data), we highlight areas around the world where, if the environmental conditions allowed its deposition and survival until today, RSL data of at least this accuracy may help to quantify the GIA modeling parameters above.

The sensitivity to ice-load history variations is the dominating pattern covering almost the whole world before about $13 \mathrm{ka}$ (calendar years before 1950). The other three parameters show distinct patterns, but are almost everywhere overlapped by the ice-load history pattern. The more recent the data are, the smaller the area of possible RSL locations that could provide enough information to a parameter. Such an area is mainly limited to the area of former glaciation, but we also note that when the accuracy of RSL data can be improved, e.g., from $2 \mathrm{~m}$ to $1 \mathrm{~m}$, these areas become larger, al-
\end{abstract}

lowing better inference of background viscosity and lateral heterogeneity. Although the patterns depend on the chosen models and error limit, our results are indicative enough to outline areas where one should look for helpful RSL data of a certain time period. Our results also indicate that as long as the ice-load history is not sufficiently known, the inference of lateral heterogeneities in mantle viscosity or lithospheric thickness will be interfered by the uncertainty of the ice model.

\section{Introduction}

Glacial isostatic adjustment (GIA) describes the response of the Earth to glacial loading and unloading processes. It includes changes in the Earth's deformation, gravity due to redistribution of mass, moment of inertia and state of stress. Hence, investigations of GIA address different fields giving among other things insight into ice-load dynamics and Earth rheology. For the latter, foci are mainly set with GIA models on lithospheric thickness and Newtonian mantle viscosities as well as their lateral variation in the Earth, respectively.

For an accurate determination of model parameters such as ice-load history, lithospheric thickness, radial and lateral variation of mantle viscosities, many geologic, geophysical and geodetic observations are used to constrain GIA models or identify the best-fitting one by comparing observations to model predictions (see, e.g., Steffen and $\mathrm{Wu}, 2011$, for an overview). Nowadays, the most commonly used observations 
are GPS measurements, which provide a highly accurate current velocity/deformation field, and gravimetric observations based on terrestrial (absolute and relative gravimetry) and space techniques, which show the deviation from equilibrium and ongoing mass redistributions (Wu et al., 2013). It should be noted that both GPS land-uplift rate and gravity rate-of-change data only give the rate of change today, which is more than 8000 years after the end of deglaciation. On the other hand, relative sea-level (RSL) data record the deformation that occurred in the past (Wu et al., 2013), especially in the last 20000 years or so since the Last Glacial Maximum. The determination of ice-load history, lithospheric thickness and mantle viscosity depends greatly on the quality and thus accuracy of the used data. Geodetic observations achieve sufficient accuracy for the detection of the GIA signal after a few years, i.e., about 5 years, of observation (Wu et al., 2010; Steffen et al., 2012). The longer the time span, the better the accuracy.

Wu et al. (2010) and Steffen et al. (2012) investigated the sensitivity of GPS and gravity observations, respectively, to four prominent GIA modeling parameters: ice-load history, lateral lithospheric thickness variation, background viscosity, and lateral viscosity variation. The major goal of the two studies was to identify optimal locations for these geodetic observations as economic, logistic and ecological reasons limit the capabilities to cover the (whole) Earth sufficiently with stations (Steffen et al., 2012). An optimal location is defined here by where sensitivity lies above the current detection accuracy of a selected geodetic observation (Wu et al., 2010).

Wu et al. (2010) studied the optimal locations for GPS measurements in North America and Fennoscandia, both areas with prominent GIA signals and already existing GPS networks. They clearly identified the region west of Hudson Bay until the Rocky Mountains as a major gap in the North American permanent GPS network. The network in northern Europe is almost adequate except in the northeast (Wu et al., 2010). Ice-load history appeared to be the best detectable parameter.

The study by Steffen et al. (2012) focused on optimal locations of terrestrial (absolute) gravity measurements in North America and northern Europe and also analyzed the sensitivity of the Gravity Recovery and Climate Experiment (GRACE) twin-satellite mission there to the four parameters. Both terrestrial measurements and GRACE observations sense the four parameters as their sensitivity is higher than the currently determined trend errors, with ice-load history being again the best detectable parameter (Steffen et al., 2012). The authors also suggested more absolute gravity stations in northwestern and Arctic Canada and a comprehensive data combination of all absolute gravity measurements in northern Europe.

This study now adds RSL data to the search for optimal locations of GIA observations to help constrain the four parameters above. RSL data have, since the beginning of GIA research, been an important data set in the understanding and modeling of the GIA process (Clark, 1980; Tushingham and Peltier, 1992, 1993; Steffen and Wu, 2011). Still, they help in constraining ancient ice history (Peltier, 2004; Horton et al., 2009; Engelhart et al., 2011), quantifying the timing of drainage of glacial lakes (Törnqvist \& Hijma, 2012) or apparent uplift of the coast since the last interglacial 125000 years ago (Pedoja et al., 2011).

The issue and analysis here is different to the former studies with geodetic data in at least three ways. First, GPS and gravity measurements represent recent measurements that determine the GIA signal today. The signal is small, i.e., about $1 \mathrm{~cm} \mathrm{a}^{-1}$ vertical change and about $2 \mu \mathrm{Gal} \mathrm{a}^{-1}$ gravity change, while RSL data may show a complete deformation curve over several thousands of years with occasionally several hundreds of meters. Thus, a geodetic signal can be considered as a snapshot of the time-delayed visco-elastic part of GIA, and the observations are "only" three-dimensional when compared to the four-dimensional (space and time) signal visible in RSL data. Hence, we compare something recent (GPS, gravity) with something from the past (RSL) (Wu et al., 2013).

Second, we cannot advise where to place instruments for adequate sea-level measurements as they have to be deposited under certain conditions in order to survive until today. While GPS and terrestrial gravity measurements are limited due to economic and/or logistic reasons, RSL data can potentially be found in all oceans and coastal areas. Also, RSL-like data such as lake levels can be found far off the coast, e.g., in Sweden (Lambeck et al., 1998a). However, there are different limitations depending on the sea-level indicator itself, the environment of its deposition, processes acting at the sample or in the area since its deposition, and many more. We thus can only indicate but not guarantee where RSL data with sufficient information could be found. In addition, we illustrate the sensitivity of RSL data on a global scale rather than the dedicated regions we had to use for geodetic observations.

Third, the sensitivity of RSL data varies with time. The same naturally holds for the sensitivity of geodetic observations as well; however, as aforementioned, geodetic measurements are only snapshots of today. Thus, we have to analyze different times when RSL data were likely deposited, but that also depends on the accuracy of current dating methods.

We will address the following questions in this paper:

- Where should RSL data be located to help constrain iceload history models, lateral lithospheric thickness variations, background viscosity and lateral viscosity variations used in GIA modeling?

- At which times are RSL data at a certain location sensitive to one of the parameters?

- How accurate should they be?

- Where should new and helpful data be searched? 
a)

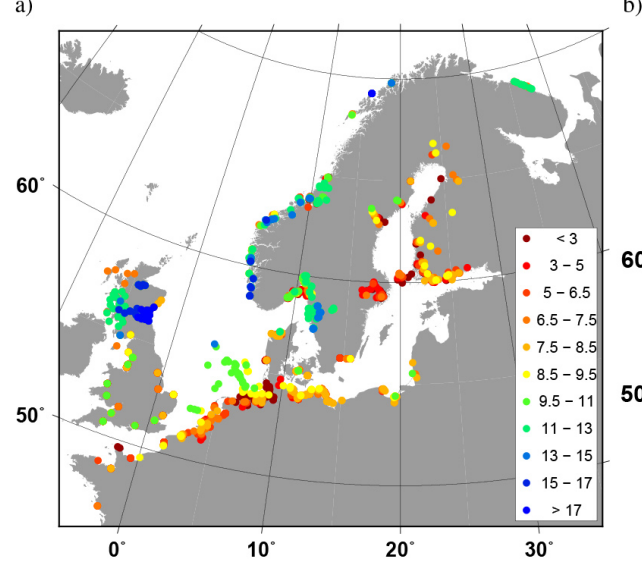

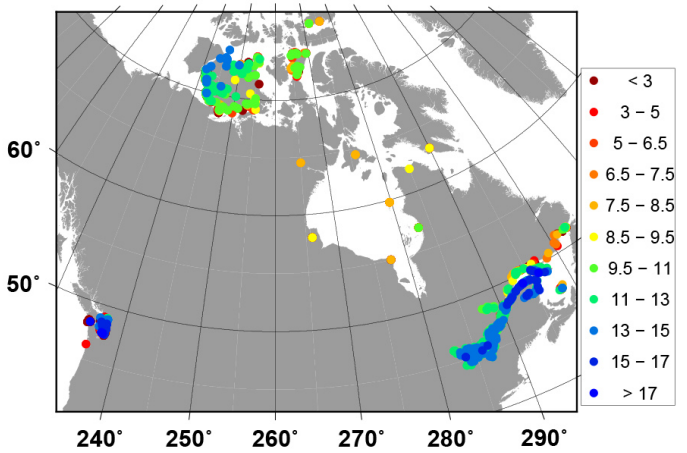

Figure 1. Exemplary overview of the location of relative sea-level data in (a) northern and central Europe and (b) North America. Colored dots highlight their age. Unit in ka (calendar years before 1950).

In the next section, we discuss RSL data, their errors and possible deposition times. This is followed by Sect. 3, which gives an introduction to the models used. Sections 4 and 5 present and discuss the results, respectively. Based on the discussion of RSL data in Sect. 2, we provide complete maps of RSL data sensitivities for nine different times in the past. Finally, the conclusion is given in Sect. 6 .

\section{Relative sea-level data}

Relative sea levels or palaeo-strandlines document the crustal response of the Earth due to glaciation and subsequent water mass redistribution between the oceans and ice sheets. The sea level at a certain time and location can be dated by shells, corals, wood, whale bones or pollen (van de Plassche, 1986). Their great benefit is that they cover a long time period of deformation, occasionally dating back to several thousand years (Steffen and $\mathrm{Wu}, 2011$ ). They are mostly dated by the ${ }^{14} \mathrm{C}$ method and thus need to be calibrated for use in GIA modeling (Fairbanks et al., 2005).

Sea-level indicators can be found in coastal and shelf areas all around the world. However, their quality and age vary from location to location as many processes such as changes in tidal range, storms, local tectonics, and compaction (see, e.g., Vink et al., 2007) influence their deposition and preservation. Also, the last ice sheets have destroyed evidence of previous shorelines, leading to a lack of data from before $20 \mathrm{ka}$ (calendar years before 1950) in formerly glaciated areas (Steffen and Wu, 2011).

In northern Europe, for example, one can find about 4000 dated sea-level indicators, with most data going back to about $15 \mathrm{ka}$ (Steffen and $\mathrm{Wu}, 2011$ ). However, not all are publicly available (see Lambeck et al., 2010). All over the world, several thousand data have been collected so far (Klemann and Wolf, 2006), and new data are added occasionally.
Figure 1 shows the distribution of RSL data in our database in northern Europe and North America. We note that more data have been published for these regions, but those have not been added yet to our database. It can be seen that older data are found outside the former margin of glaciation. The closer the data are located to the last remnants of the ice sheets, the younger they are. The flooding of the southern North Sea is also mirrored in older data in the sea and younger data near the coast (Vink et al., 2007).

Now, each sample of a database has an associated error or uncertainty in height and time. This is different to GPS and gravity measurements, which are usually provided with an error in velocity or gravity rate of change, respectively. Thus, when investigating the observational error of RSL data one has to consider two errors. However, the time error of RSL data is often converted into an additional height error (Lambeck et al., 1998b) to ease a misfit calculation. The height error then includes the effect $|\mathrm{d} h / \mathrm{d} t|_{t} \sigma_{t}$ (Lambeck et al., 1998b), where $|\mathrm{d} h / \mathrm{d} t|_{t}$ is the rate of sea-level change at time $t$ and $\sigma_{t}$ the age error. The rate of sea-level change is usually taken from a rebound model, which is determined as part of an iterative solution in ice-model developments (Lambeck et al., 2010). Hence, the height error becomes larger, while the time error is set to zero. For further discussion of error sources in RSL data the reader is referred to Lambeck et al. (1998b).

As an example, we analyze our available data sets for North America and northern Europe (including the British Isles) for their errors. The aim of this exercise is to find a reliable average error that will be applied in this investigation. For the 11 time periods that we analyze in total (see Sect. 4), we group our data accordingly into subsets of 1000 or 2000 years in duration. Figure 2 shows the average and maximum RSL data errors in North America and northern Europe. About 3700 data samples were analyzed, which cover a large range in time and space. We thus consider our determined 


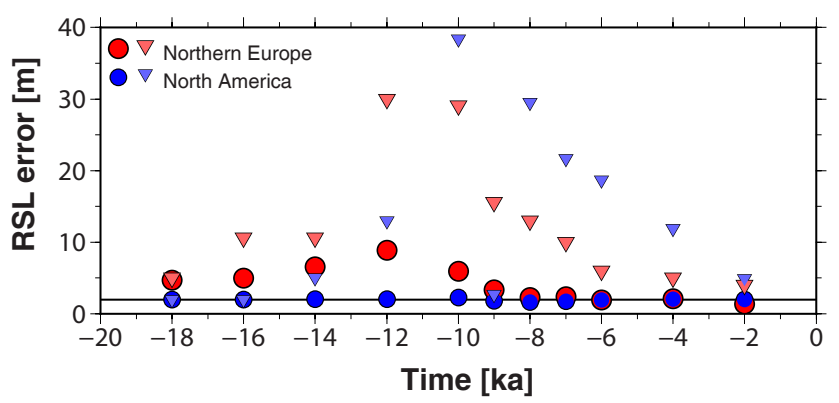

Figure 2. Average (circles) and maximum (inverted triangles) errors of relative sea-level data in North America (blue) and Europe (red) in time subsets of 1000 (between 10 and $6 \mathrm{ka}$ ) or 2000 years. Average calculated as arithmetic mean. In total about 3700 were analyzed for this example.

average value below to be representative of all possibly available RSL data.

Groups of younger samples contain many hundreds of samples, while groups with older samples, e.g., of $14 \mathrm{ka}$ and older, envelop only a few. The maximum error becomes larger as the subset gets older, peaking at 10 (North America) and $12 \mathrm{ka}$ (northern Europe), and then becoming much smaller (especially for North America). However, the number of older data is, as outlined above, much smaller than the number of younger data, therefore this error range is biased by the number of samples in each time span. One should also consider that the database partly contains samples analyzed a few decades ago when dating methods were not as sophisticated as today, thus such samples may have larger errors. These errors may increase the average error of a time span. It is beyond the aims of this study to evaluate each of the 3700 data samples to see how and when they were dated, so we shall use our database as a typical example and hope that this high number of samples allows us to perform a robust analysis.

North American data overall support an average error value of $2 \mathrm{~m}$ during all time subsets (thin solid black line in Fig. 2). Fennoscandian data show a higher average than $2 \mathrm{~m}$ for $10 \mathrm{ka}$ and older. However, we hope as more newly determined data are added to these time subsets that the average will become lower. For example, new data for the southern North Sea show mainly errors of much less than a meter (Vink et al., 2007). Thus, we set $2 \mathrm{~m}$ as limit in this study, but we will also test in two examples how a better error of $1 \mathrm{~m}$ as well as an extreme value of $8 \mathrm{~m}$ (e.g., the average error of Fennoscandian data at $12 \mathrm{ka}$ ) affect our results.

\section{Modeling}

The models and approach used are taken from $\mathrm{Wu}$ et al. (2010) and Steffen et al. (2012). We use a reference model with $115 \mathrm{~km}$ lithospheric thickness as well as $6 \times 10^{20} \mathrm{Pas}$,
$3 \times 10^{21} \mathrm{~Pa}$ s and $6 \times 10^{21} \mathrm{Pas}$ as background viscosity in the upper, shallower lower and deep lower mantle, respectively. The ice-load history is taken from model ICE-4G (Peltier, 1994). It is employed as surface load on a 2-degree grid of a non-rotating, spherical, self-gravitating, Maxwell viscoelastic finite-element earth model that includes material compressibility and self-gravitating oceans. We systematically vary, one at a time, the four previously mentioned parameters in the model to test its sensitivity in the global RSL predictions. The reference model and all the varied parameters can be found in Table 1.

For the sensitivity to the ice model, we compare the response between ICE-4G and ICE-5G (Peltier, 2004) globally (which differ not only in the Northern Hemisphere but also in Antarctica). For the other three parameters we apply the same changes as in Steffen et al. (2012). The model of lateral heterogeneous lithospheric thickness in Wu et al. (2005) is used instead of a $115 \mathrm{~km}$ uniformly thick lithosphere. The background viscosity is changed to $7 \times 10^{20} \mathrm{~Pa}$ in the upper mantle and $10^{22} \mathrm{~Pa}$ s throughout the lower mantle. Thus, we modify a VM2-like model (Wu et al., 2013) with a slight gradual viscosity change from the upper to the lower mantle to one with a higher viscosity contrast with depth. The lateral heterogeneous mantle viscosity is implemented from model RF3S20 by Wang et al. (2008).

As in former studies, we caution that the model parameters used represent typical cases only. We do not provide definitive sensitivity results as we apply selected models for iceload history, lateral lithospheric thickness and viscosity, and there exists a broad variety of models and opinions for each parameter. There is, for example, still no consensus about how viscosity increases with depth in the mantle (Steffen and Wu, 2011; Wu et al., 2013). Hence, it is rather our goal to give a feel of what sensitivity one may expect in general, and also where we can expect or look for RSL data that may help solve problems still under debate.

\section{Results}

We plotted the sensitivity kernels at 11 different times between $18 \mathrm{ka}$ and $2 \mathrm{ka}$. Time steps are 2000 years, but we also included the sensitivity for 9 and $7 \mathrm{ka}$, as the large continental ice sheets vanished rapidly from $10 \mathrm{ka}$ until $6 \mathrm{ka}$. For this paper, we only show two distinct examples out of the large number of 44 figures or subplots. The first is an overview of 6 sensitivity patterns for a changed ice-load history at 18,16 , 14, 12, 10 and $8 \mathrm{ka}$ in Fig. 3 to show the temporal pattern change of a parameter. The other example is the sensitivity of each parameter at $7 \mathrm{ka}$ to compare four patterns at a dedicated time. As deposition of sea-level indicators or similar samples is not possible in glaciated areas on land, we mark these areas in the figures by drawing the extent of the ice at that time from model ICE-5G. 
Table 1. Model parameters for the reference model and other models for sensitivity tests. LT: lithospheric thickness; UM: upper-mantle viscosity (above $670 \mathrm{~km}$ depth); LM1: shallow lower-mantle viscosity (670-1171 km depth); LM2: deep lower-mantle viscosity (1171 km to core-mantle boundary).

\begin{tabular}{|c|c|c|c|c|c|}
\hline Effect of & $\begin{array}{l}\text { Ice } \\
\text { model }\end{array}$ & $\begin{array}{c}\mathrm{LT} \\
{[\mathrm{km}]}\end{array}$ & $\begin{array}{c}\mathrm{UM} \\
{[\mathrm{Pa} \mathrm{s}]}\end{array}$ & $\begin{array}{l}\text { LM1 } \\
{[\mathrm{Pa} \mathrm{s}]}\end{array}$ & $\begin{array}{l}\mathrm{LM} 2 \\
{[\mathrm{~Pa} \mathrm{~s}]}\end{array}$ \\
\hline Reference model & ICE-4G & 115 & $6 \times 10^{20}$ & $3 \times 10^{21}$ & $6 \times 10^{21}$ \\
\hline Ice model & ICE-5G & 115 & $6 \times 10^{20}$ & $3 \times 10^{21}$ & $6 \times 10^{21}$ \\
\hline $\begin{array}{l}\text { Lat. heterogeneous } \\
\text { lithosphere }\end{array}$ & ICE-4G & $\begin{array}{c}\text { Lat. het. lith } \\
\text { (Wu et al., 2005) }\end{array}$ & $6 \times 10^{20}$ & $3 \times 10^{21}$ & $6 \times 10^{21}$ \\
\hline Background viscosity & ICE-4G & 115 & $7 \times 10^{20}$ & $10^{22}$ & $10^{22}$ \\
\hline $\begin{array}{l}\text { Lat. heterogeneous } \\
\text { viscosity }\end{array}$ & ICE-4G & 115 & \multicolumn{3}{|c|}{$\begin{array}{c}\text { Lat. het. mantle RF3S20 with } \\
\beta=0.4 \text { (Wang et al., 2008) }\end{array}$} \\
\hline
\end{tabular}

Figure 3 clearly shows the areas of highest sensitivity to changes in ice-load history, e.g., more than $600 \mathrm{~m}$ are located under the ice in North America at $18 \mathrm{ka}$. As it is unlikely to find samples under ice coverage, we focus on ice-free areas. At $18 \mathrm{ka}$, significant sensitivities are found in northern Russia, which is related to differences in the ice models. We therefore draw the ice extent according to model ICE$4 \mathrm{G}$ with a green line to allow a rigorous analysis. The extent of the Barents and Kara seas ice sheet in ICE-4G at $18 \mathrm{ka}$ is much farther to the east, resulting in a notable sensitivity signal. Another area is found farther east in the Chukchi Sea, where ICE-4G contains a glaciation. Both areas show sensitivities of more than $200 \mathrm{~m}$, while it is much less than $100 \mathrm{~m}$ in all other areas (e.g., in Antarctica). This behavior continues through time as long as the ice sheets remain significantly on land. At about $12 \mathrm{ka}$ (Fig. 3d) we find a prominent retreat east of the Rocky Mountains uncovering high sensitivities of up to $400 \mathrm{~m}$ due to significant differences in ice thickness west of Hudson Bay between the two ice models used. Sensitivities of $100 \mathrm{~m}$ and more still exist at $7 \mathrm{ka}$ (Fig. 4a). In Scandinavia, sensitivities are not that large, but can also reach $50 \mathrm{~m}$ at $10 \mathrm{ka}$ (Fig. 3e). Similar features are found around Antarctica. In all other areas sensitivities are much lower.

Compared to the solid Earth parameters (see Fig. 4), iceload history has significantly larger sensitivity. RSL data are mainly sensitive to lithospheric thickness variations in formerly glaciated areas and also around still glaciated ones. Values of about $12 \mathrm{~m}$ are reached. Sensitivity to background viscosity is constrained to the Hudson Bay area and the Antarctic coast. Areas of lower sensitivity can be found around the Arctic and in British Columbia. For sensitivity to lateral viscosity variations, RSL data should be checked in North America, Fennoscandia and the Barents Sea.

Next, we show the places where the sensitivity of the RSL data exceeds $2 \mathrm{~m}$. Figures 5-7 show the superposition of the sensitivity pattern (above $2 \mathrm{~m}$ error) of all four parameters at eight selected times. As it may be possible one day to determine heights above sea level in past times far inland and to allow a better comparison of the pattern change over time, contours on-land are also shown.

As mentioned earlier, the dominant parameter in these figures is ice-load history. Samples dated to $18 \mathrm{ka}$ are sensitive to it almost everywhere in the world (Fig. 5a, red lines), with the exception of the southern Indian Ocean. As we shall see in Fig. 8, the highlighted area will change if the error of the RSL data is different from $2 \mathrm{~m}$. At later times (Fig. 5b and c), RSL data from all over the world are sensitive to ice-load history. At $12 \mathrm{ka}$ (Fig. 5c), the pattern shows low sensitivities in the circum-antarctic oceans. This white space is shifted 2000 years later to north of the Equator, with a low-sensitivity region around some parts of the Mediterranean and the Black Sea (e.g., Fig. 6). Thereafter, the whole white space expands until $2 \mathrm{ka}$ (Fig. 7b), pushing back areas of higher sensitivity to the (formerly) glaciated regions and leaving local sensitivity areas above $2 \mathrm{~m}$ error at certain times. The latter can be found, for example, at $7 \mathrm{ka}$ in South America, southern Africa and Australia (Fig. 6c). Most coastal areas far away from the former glaciation are insensitive. This has held, for example, since $10 \mathrm{ka}$ for a major part of the Mediterranean and some parts of the Caribbean. In comparison to areas sensitive to ice-load history, areas sensitive to lithospheric thickness variations are much smaller. They are found near the ice sheets or formerly glaciated areas (Fig. 5a, green lines), and the behavior of the pattern remains throughout all times. At $2 \mathrm{ka}$ (Fig. 7b), sensitive areas remain at the Antarctic Peninsula, the northern Gulf of Bothnia and Baffin Bay.

Sensitivity to background viscosity covers larger areas than sensitivity to lithospheric thickness variations. Almost all areas north of $45^{\circ} \mathrm{N}$, South America, parts of Africa, East Asia, Australia and Antarctica show a sensitivity above $2 \mathrm{~m}$ at $18 \mathrm{ka}$ (Fig. 5a, blue dots). This pattern does not change significantly until $12 \mathrm{ka}$ (Fig. 5c). Thereafter, the behavior is similar to lithospheric thickness variations, although they cover larger areas. At $2 \mathrm{ka}$ (Fig. 7b), only a few spots (southern James Bay, the northern Gulf of Bothnia and the Barents Sea) are left in the Northern Hemisphere. Lateral variations 
a)

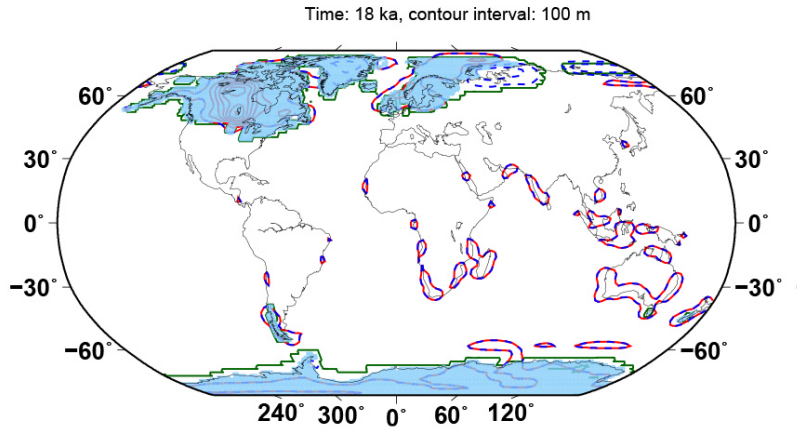

b)

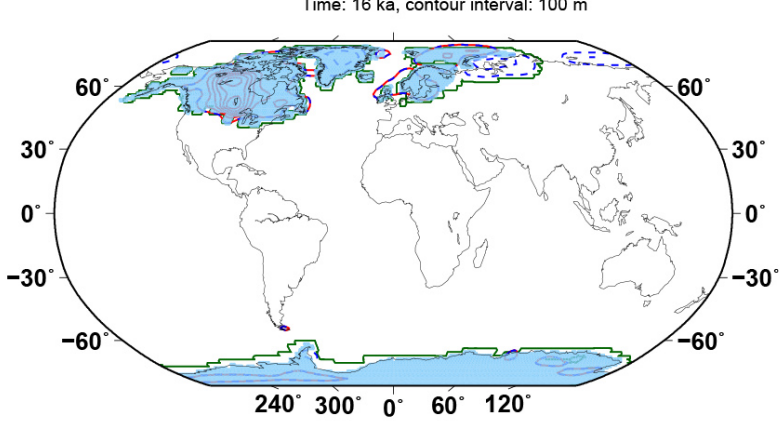

c)

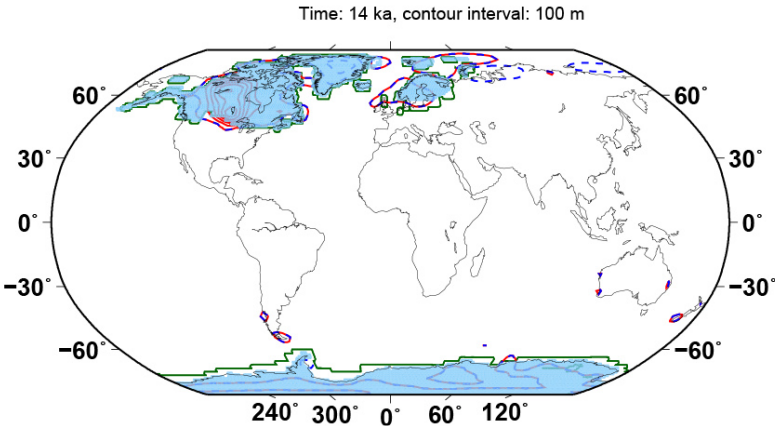

d)

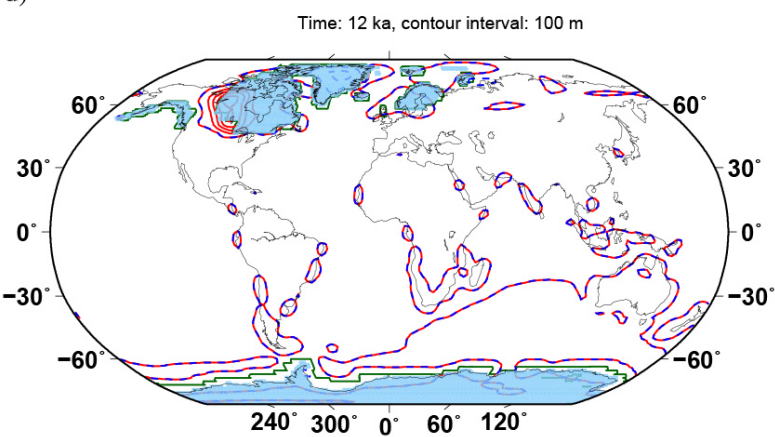

e)

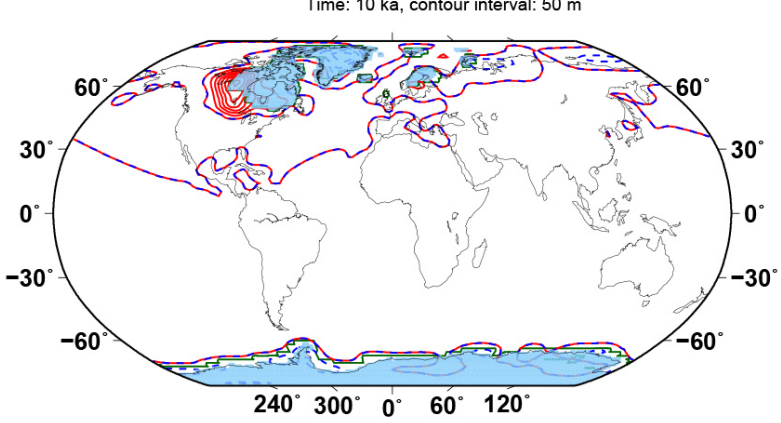

f)

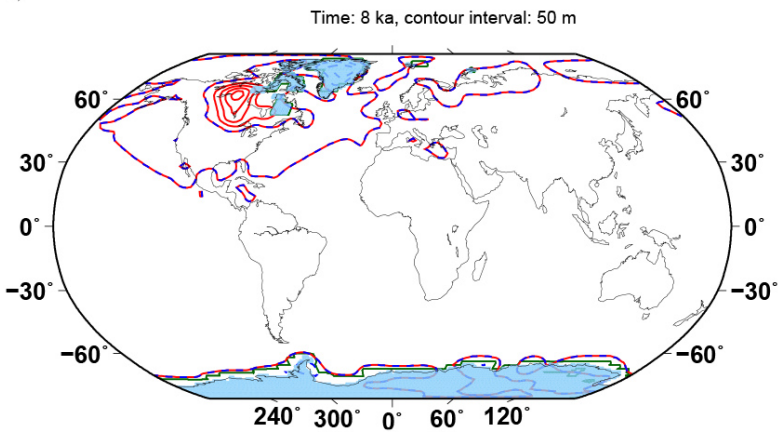

Figure 3. Sensitivity of relative sea-level data around the world to changes in ice model at (a) 18 , (b) 16, (c) 14 , (d) 12 , (e) 10 and (c) $8 \mathrm{ka}$. Light blue areas mark the extent of ice sheets at the time, taken from the ICE-5G model (Peltier, 2004). Green solid line marks the ice extent from the ICE-4G model (Peltier, 1994). Red and blue-dashed lines are contours with positive and negative sensitivity, respectively. The red-blue-dashed line marks zero sensitivity. Contour intervals indicated on top. Unit in $\mathrm{m}$. To read the sensitivity of a certain line, count the number of lines from the zero-sensitivity line and multiply by the contour interval.

in viscosity show the most diverse sensitivity patterns. From $18 \mathrm{ka}$ (Fig. 5a, purple lines) until 14 ka (Fig. 5b), many sensitivity areas are determined next to the immediate surrounding of the ice sheets, e.g., the western and northeastern coasts of South America or the northwestern coasts of Africa and Australia. In the following millennia the areas are more constrained to the near surrounding of the (formerly) glaciated areas. At $2 \mathrm{ka}$ (Fig. 7b), there are only a few very small areas on land left in North America and the Lofoten in Fennoscandia.

In the following we analyze how the pattern at a specific time changes if a different error is assumed. Figure 8 shows the effect of error size ( $1 \mathrm{~m}$ for (a), $2 \mathrm{~m}$ for (b) and $8 \mathrm{~m}$ for (c)) on the pattern for $10 \mathrm{ka}$. The latter represents a rather extreme case, while an error of $1 \mathrm{~m}$ is a likely improvement for more recently discovered and dated samples. Any pattern at a specific time will not change significantly if the error value is changed moderately, e.g., by a few decimeters. If the value is changed significantly to higher or lower values, the pattern of a parameter will decrease or increase its sensitivity area accordingly. To understand why the area increases when the error value decreases, note that the plotted areas have sensitivity values (e.g., Figs. 3 and 4) above the error value. Thus a smaller error value means more area can be sensitive to that parameter variation. When the error changes from 2 to $1 \mathrm{~m}$, the global sensitivity pattern of 
a)

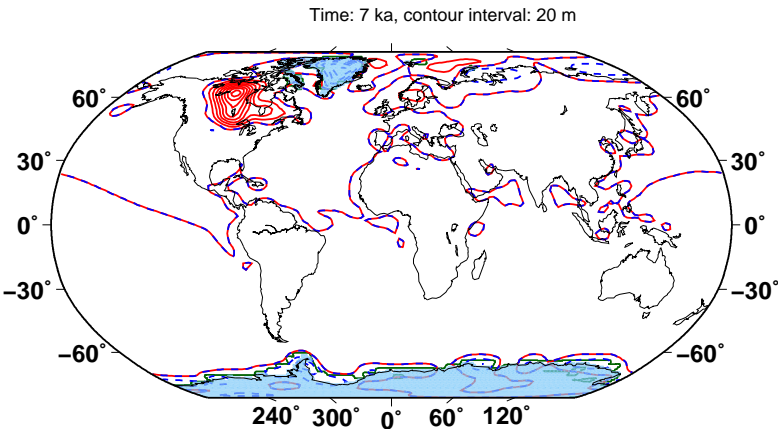

c)

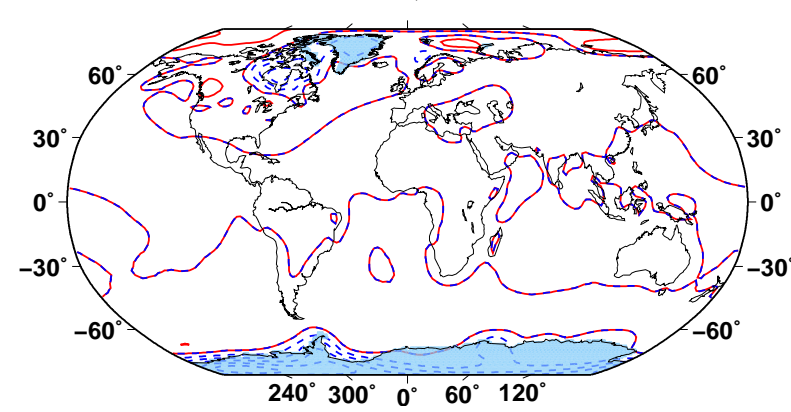

b)

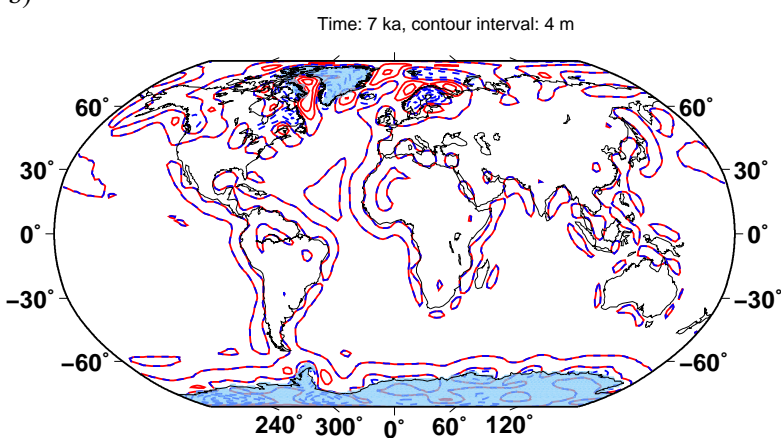

d)

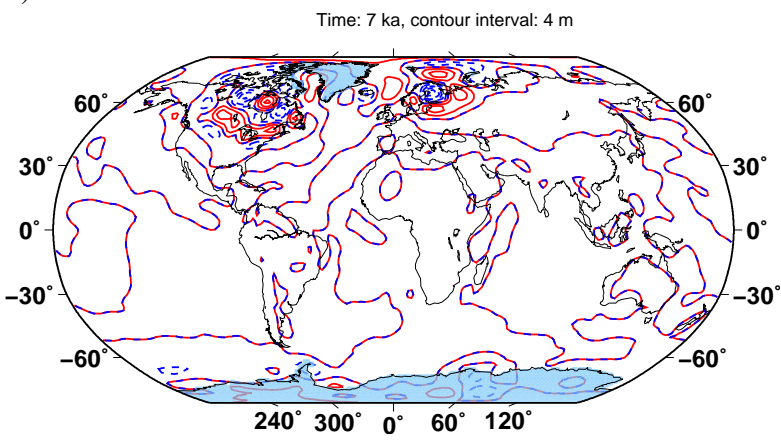

Figure 4. Sensitivity of relative sea-level data around the world to changes in ice-load history model (a), lithospheric thickness variations (b), background viscosity (c), and lateral viscosity variations (d) at $7 \mathrm{ka}$. Light blue areas mark the extent of ice sheets at the time, taken from the ICE-5G model (Peltier, 2004). Red and blue-dashed lines are contours with positive and negative sensitivity, respectively. The red-blue-dashed line marks zero sensitivity. Contour intervals indicated on top. Unit in $\mathrm{m}$. To read the sensitivity of a certain line, count the number of lines from the zero-sensitivity line and multiply by the contour interval.

ice-load history shows mainly the same signature as for an error of $2 \mathrm{~m}$, but the area becomes larger, reducing the insensitive areas in the Caribbean and the Mediterranean. For the solid Earth parameters the patterns increase more drastically around the Equator. When raising the error to $8 \mathrm{~m}$, the area for all parameters is reduced significantly. Sensitivity to the solid Earth parameters is now mainly found near glaciated areas, whereas background viscosity sensitivity areas are quite small and restricted.

\section{Discussion}

The high sensitivity of RSL data to ice-load history changes over all millennia and almost independent of the chosen error confirms that RSL data play an outstandingly important role in the development of ice models, especially on a global scale. The reason is due to the relationship between the sealevel changes and ice coverage via the sea-level equation (Farrell and Clark, 1976): the higher the amount of ocean water bound in ice sheets at a certain time, the larger the sensitivity areas. Well-known sea-level fingerprints from the ice sheets (e.g., Mitrovica et al., 2001) appear in the sensitivity pattern of the RSL data, which confirms a link of selected, but not all RSL data to a certain ice sheet (Peltier, 2004; Horton et al., 2009). Areas of interest for improving ice-load history are the eastern coast of the United States, the southern coasts of South America, Africa and Australia as well as the coast of Antarctica. Southern Hemisphere RSL data of $7 \mathrm{ka}$ and older probably help in constraining the Antarctic Ice Sheet history. Data from the US east coast (from $18 \mathrm{ka}$ until $6 \mathrm{ka}$ ), the Canadian coast and shelves (from $10 \mathrm{ka}$ until $4 \mathrm{ka}$ ) and the Hudson Bay (from about $8 \mathrm{ka}$ on) should help in constraining the Laurentide Ice Sheet, which confirms Horton et al. (2009) and Simon et al. (2011). We also note a corridor between the Rocky Mountains and Hudson Bay from about $12 \mathrm{ka}$ on, where lake-level data of former and still existing lakes may be found. In Fennoscandia both the North and Baltic seas highlight sufficient sensitivities from $14 \mathrm{ka}$ on. RSL data that are sensitive to lithospheric thickness can only help in quantifying variations near the ice sheets if the ice-load history is accurately known. This is due to the overlap between the ice-load history sensitivity pattern and that due to lithospheric variations. Sites far away from any ice sheets (e.g., Africa) will not provide insight into the underlying lithosphere structure. As background viscosity controls the amount of lithospheric depression due to the ice load and thus influences vertical movements and ocean geometry, the pattern at glacial maximum is clearly characterized by a 


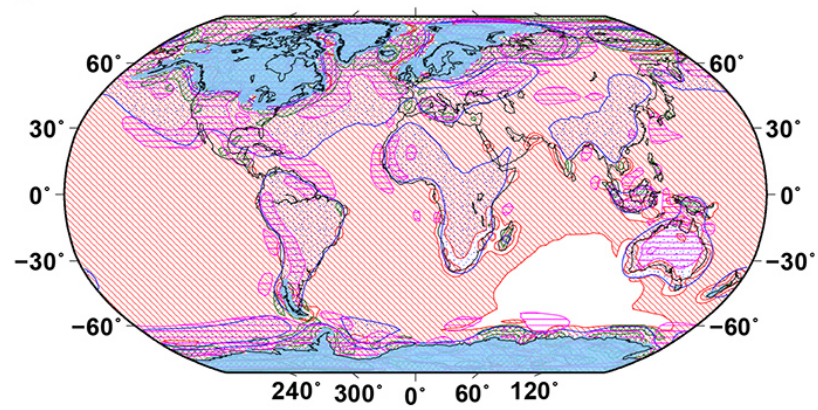

b)

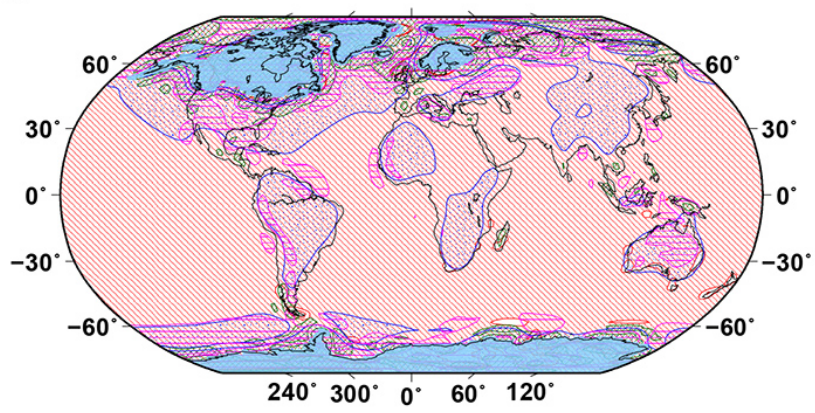

c)
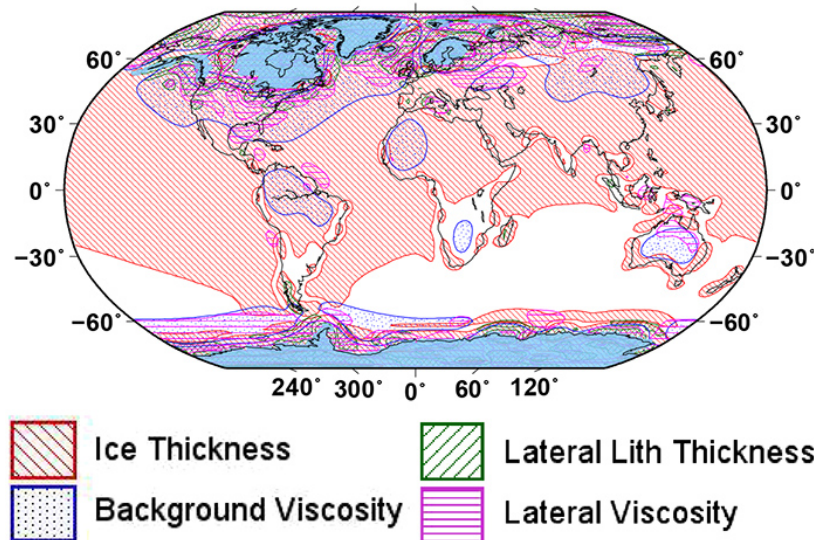

Lateral Lith Thickness Lateral Viscosity

Figure 5. Sensitivity of relative sea-level data around the world above an assumed error of $2 \mathrm{~m}$ to changes in ice-load history model (see text, red area, lines from top left to bottom right), lithospheric thickness variations (green, lines from top right to bottom left), background viscosity (blue dots), and lateral viscosity variations (pink, horizontal lines) at (a) 18, (b) 14 and (c) $12 \mathrm{ka}$. If a color does not appear, then the sensitivity of this parameter lies below the error. Light blue areas mark the extent of ice sheets at the time, taken from the ICE-5G model (Peltier, 2004).

mixture of high sensitivities in and around the glaciated areas as well as in other high sensitivities. Thus, older far field RSL data may help determine background viscosity if the ice thickness is known satisfactorily. This statement may be altered if the error of RSL data decreases to $1 \mathrm{~m}$ or smaller. This can be seen in Fig. 8a in an area in the northern Pacific, where the patterns of background viscosity and ice-load history do not overlap. Such a non-overlapping area also exists a)

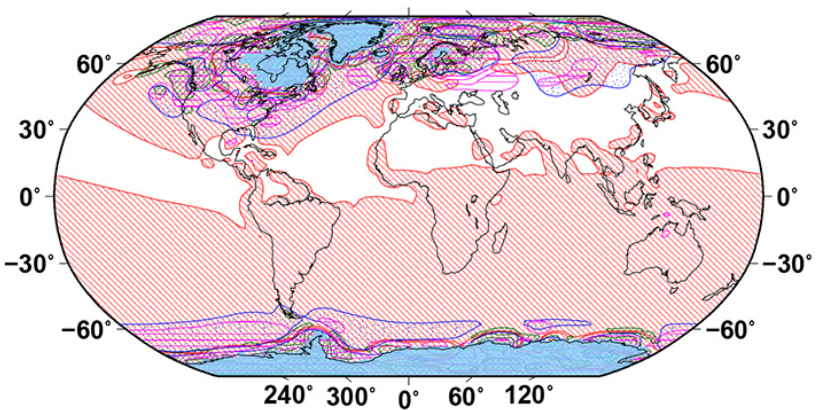

b)

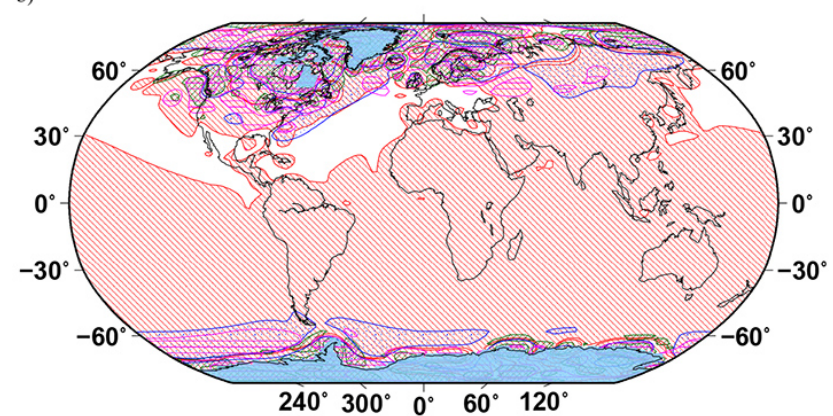

c)

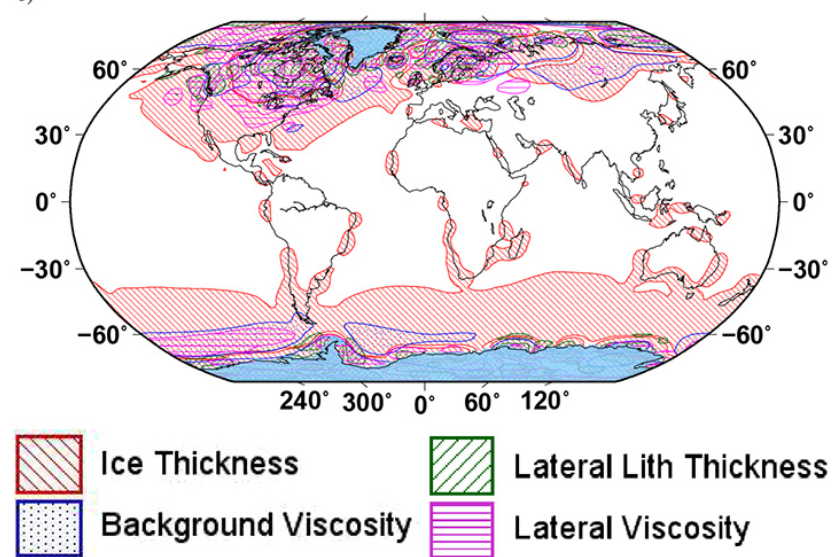

Figure 6. Same as Fig. 5, but for (a) 9, (b) 8 and (c) 7 ka.

for other times if the RSL error is $1 \mathrm{~m}$ or smaller. The area for lateral variations in mantle viscosity also overlaps with that for ice-load history, so lateral viscosity variations can only be determined if the ice-load history is known accurately. However, one should caution that the sensitivity pattern of lateral variations in mantle viscosity is affected by the model of lateral variations. The $2 \mathrm{~m}$ error needs to be compared to the deformation and/or sea-level change at a certain time in an area of interest. Sensitivity exceeds $2 \mathrm{~m}$ during glaciation (18-7 ka) almost everywhere including where RSL data can be expected. After glaciation ( $7 \mathrm{ka}$ until the present day) the sensitivity area becomes smaller, as the (calculated) deformation or sea-level change can be less than $2 \mathrm{~m}$. However, more recent RSL data often have errors smaller than $2 \mathrm{~m}$, which enlarges the sensitivity pattern for each parameter shown in 
a)

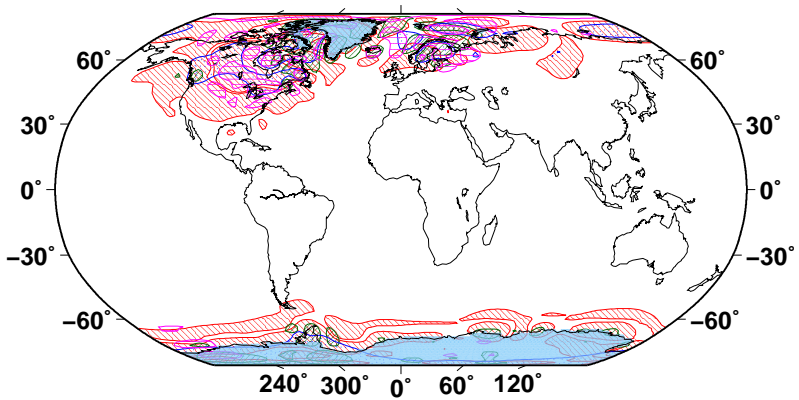

b)

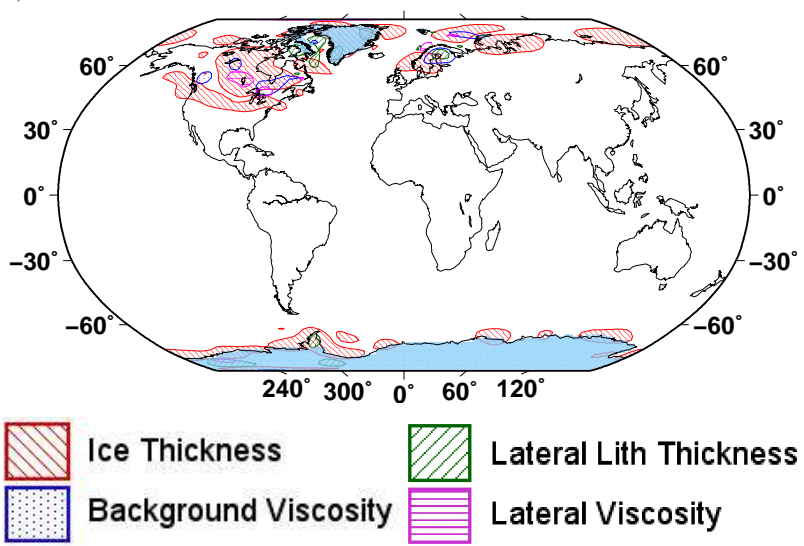

Figure 7. Same as Fig. 5, but for (a) 4, and (b) 2 ka.

Figs. 5-7. Thus, samples from other areas may be used in case their error is smaller than the new limit. In our example using a $1 \mathrm{~m}$ error limit (Fig. 8), the pattern for ice-load history shows the smallest variation as the sensitivity in sea level at a specific time between the two tested ice models reaches several hundreds of meters, see Fig. 3. In comparison to that, the other three parameters have smaller sensitivities (Fig. 4), and thus a small change in the error limit can lead to significant changes in each pattern. The general findings of our study will thus not be affected if a moderately different error (e.g., a difference of a few decimeters) than $2 \mathrm{~m}$ would be chosen. The difference can be larger though when investigating ice-load history, as an increase by a factor of 4 (from 2 to $8 \mathrm{~m}$ ) still highlights its typical pattern, but is reduced in the equatorial area. The other three parameters need accurate RSL data and a precise ice-load model for their determination. The dominant sensitivity signal of ice-load history supports the findings of Wu et al. (2010) to GPS measurements and Steffen et al. (2012) to gravity observations. As RSL data illustrate vertical deformation, the pattern shape of all sensitivities in Fennoscandia and North America has strong similarities to the sensitivity pattern of the vertical component from GPS and gravity measurements. This holds especially for 4 and $2 \mathrm{ka}$, the times closest to GPS and gravity measurements today. a)

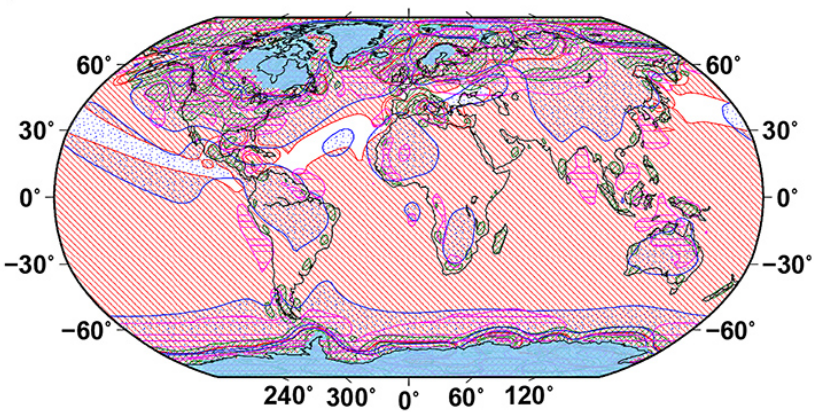

b)

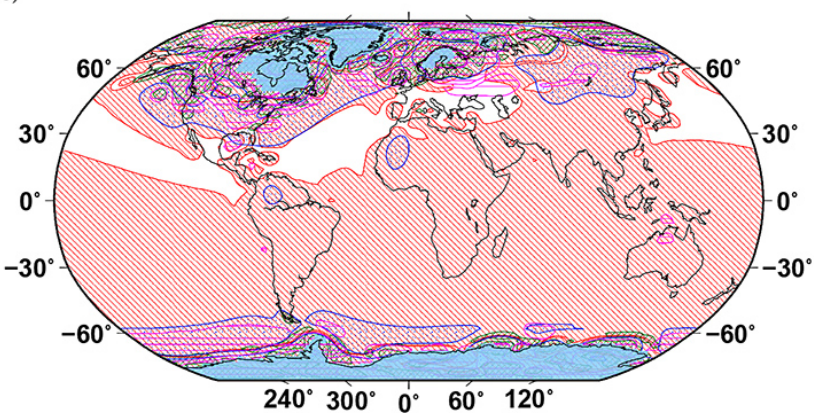

c)

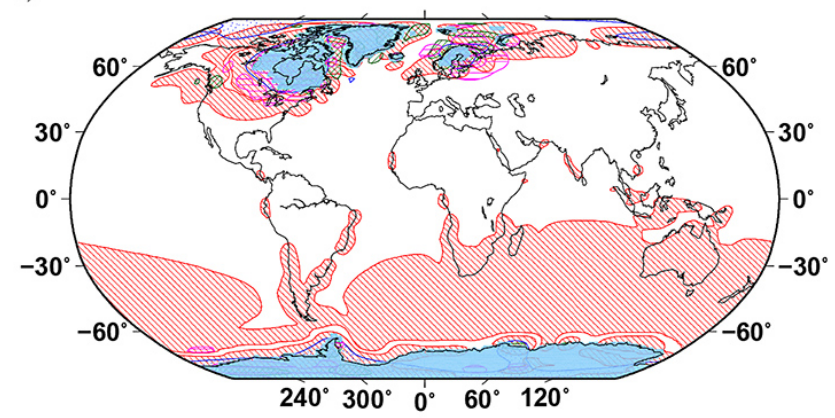

Ice Thickness

Background Viscosity

Lateral Lith Thickness

Lateral Viscosity

Figure 8. Same as Fig. 5, but for $10 \mathrm{ka}$ and different RSL data errors of (a) 1 , (b) 2 and (c) $8 \mathrm{~m}$.

\section{Conclusions}

We provide global sensitivity pattern maps of RSL data from the time of the Last Glacial Maximum until $2 \mathrm{ka}$ for four parameters that are important in GIA modeling: ice-load history, lateral lithospheric thickness variations, background viscosity, and lateral mantle viscosity variations. Our maps do not exclude the deep sea and the continents as we hope that future methods will give similar information as nearcoastal RSL data today.

Ice-load history dominates the sensitivity maps and generally overlaps with the patterns of the other three parameters. This has implications for studies of the other three parameters: as long as the ice-load history is not sufficiently known, lateral heterogeneities in mantle viscosity or lithospheric 
thickness (also background viscosity, but to a lesser degree) can only be poorly determined, as their influence is rather low when compared to the effect of ice-load history, which is dominant if the difference between ICE-4G and ICE-5G is representative of the ice thickness uncertainty. Recent studies (e.g., Argus and Peltier, 2010) indicate that it is likely an over-estimate. Also, it should be noted that the level of interference depends on the magnitude of the uncertainty in ice thickness. The level of interference decreases rapidly as the difference between the time of the ice-thickness uncertainty and the time of the RSL data increases. In addition, it should be evaluated whether rheologic changes in the oceans, e.g., due to subduction zones (Austermann et al., 2013), influence our assumptions.

In view of the dominant ice-load history sensitivity pattern, we speculate that for investigations of glacial cycles older than the last Pleistocene one, it may not be necessary to include lateral heterogeneities as the ice history of these glacial cycles is less well constrained than the late Pleistocene. However, further research is recommended. The three solid-earth parameters are mainly constrained to areas of former glaciation. The area of all patterns decreases with time. These distinct patterns depend on the background models and the chosen error limit. The latter can be changed within a few decimeters to give similar results, which especially holds for sensitivity to ice-load history, but a larger change in the error limit alters the pattern significantly.

In view of improvements in the data error, e.g., when reducing the error from $2 \mathrm{~m}$ to $1 \mathrm{~m}$, more locations, even outside the near field of GIA, can be used to infer parameters such as background viscosity and lateral heterogeneity. In particular, studies of background viscosity can be in a better situation if the error for RSL is reduced to $1 \mathrm{~m}$ or less.

Due to the dominant overlapping signal of ice-load history, one has to distinguish between regions sensitive to one, two, three or all four parameters. Assuming that ice-load history is thoroughly investigated and well determined in the future, RSL data sensitive to only one of the other three may help to constrain that particular parameter. The results will improve GIA modeling significantly and may also help in initiatives such as PALSEA (Siddall and Milne, 2012), i.e., may guide coastal geomorphologists and ocean scientists to check locations of potential RSL data helpful in GIA studies and thus may foster and trigger new mutually beneficial cooperation between the GIA modeling community and the deep-sea drilling community.

Our sensitivity study suggests the value of collecting and interpreting RSL data in coastal areas that are surrounded by deeper ocean and that non-marine fresh water lakes also provide valuable new information to constrain models.

At least 14000 RSL data samples have been determined in the last decades around the world (see, e.g., Klemann and Wolf, 2006; Lambeck et al., 2010). However, not all are easily accessible for everyone, thus we cannot clearly evaluate if this database is sufficient and present a definite recommen- dation for new data to be looked for. Of course, more data are always better, needed and greatly appreciated! However, one has to investigate thoroughly if new data improve our understanding of the GIA and the Earth's interior. Wu et al. (2013), for example, noted that sensitivity of RSL data to lowermantle viscosity is constrained to lie in formerly glaciated areas. Our results indicate now that this argument is valid for RSL data from about $6 \mathrm{ka}$ until today, but is not the case for much older RSL data. In any case, adding hundreds of newly determined far-field data that are dated to about $6 \mathrm{ka}$ and younger may introduce error to such an investigation.

As RSL data cover both spatial and temporal effects of GIA and therefore provide additional information to geodetic measurements performed on land, a combined solution from many different GIA observations is recommended in GIA investigations as long as their measurement errors allow such an analysis.

Acknowledgements. We are grateful for the constructive comments by two anonymous reviewers. The finite-element calculation was performed with the ABAQUS package from Simulia. This research is supported by an operating grant from NSERC of Canada to Patrick $\mathrm{Wu}$ and Hansheng Wang is supported by the National Natural Science Foundation of China (grant nos. 40825012, 41021003, 41174016, 41274026 and 41204013), the National Key Basic Research Program of China (973 Program, grant no. 2012CB957703) and the CAS/SAFEA International Partnership Program for Creative Research Teams (KZZD-EW-TZ-05). The figures in this paper are drawn using the GMT graphics package (Wessel \& Smith, 1998).

Edited by: B. Vermeersen

\section{References}

Argus, D. F. and Peltier, W. R.: Constraining models of postglacial rebound using space geodesy: a detailed assessment of model ICE-5G (VM2) and its relatives. Geophys. J. Int., 181, 697-723, doi:10.1111/j.1365-246X.2010.04562.x, 2010.

Austermann, J., Mitrovica, J. X., Latychev, K., and Milne, G. A.: Barbados-based estimate of ice volume at Last Glacial Maximum affected by subducted plate, Nat. Geosci., 6, 553-557, doi:10.1038/ngeo1859, 2013.

Clark, J. A.: The reconstruction of the Laurentide Ice Sheet of North America from sea level data: Method and preliminary results, J. Geophys. Res., 85, 4307-4323, doi:10.1029/JB085iB08p04307, 1980.

Engelhart, S. E., Peltier, W. R., and Horton, B. P.: Holocene relative sea-level changes and glacial isostatic adjustment of the U.S. Atlantic coast, Geology, 39, 751-754, doi:10.1130/G31857.1, 2011.

Fairbanks, R. G., Mortlock, R. A., Chiu, T. C., Cao, L., Kaplan, A., Guilderson, T. P., Fairbanks, T. W., Bloom, A. L., Grootes, P. M., and Nadeau, M. J.: Radiocarbon calibration curve spanning 0 to 50,000 years BP based on paired ${ }^{230} \mathrm{Th} /{ }^{234} \mathrm{U} /{ }^{238} \mathrm{U}$ 
and ${ }^{14} \mathrm{C}$ dates on pristine corals. Quat. Sci. Rev., 24, 1781-1796, doi:10.1016/j.quascirev.2005.04.007, 2005.

Farrell, W. E., and Clark, J. A.: On postglacial sea level, Geophys. J. R. Astr. Soc., 46, 647-667, doi:10.1111/j.1365246X.1976.tb01252.x, 1976.

Horton, B. P., Peltier, W. R., Culver, S. J., Drummond, R., Engelhart, S. E., Kemp, A. C., Mallinson, D., Thieler, E. R., Riggs, S. R., Ames, D. V., and Thomson, K. H.: Holocene sea-level changes along the North Carolina Coastline and their implications for glacial isostatic adjustment models, Quat. Sci. Rev., 28, 1725-1736, doi:10.1016/j.quascirev.2009.02.002, 2009.

Klemann, V. and Wolf, D.: A global data base for late-glacial and Holocene sea-level indicators. Poster presented at WCRP Workshop "Understanding Sea-Level Rise and Variability", Paris, 6-9 June, 2006.

Lambeck, K., Smither, C., and Ekman, M.: Tests of glacial rebound models for Fennoscandia based on instrumented sea- and lake-level records. Geophys. J. Int., 135, 375-387, doi:10.1046/j.1365-246X.1998.00643.x, 1998a.

Lambeck, K., Smither, C., and Johnston, P.: Sea-level change, glacial rebound and mantle viscosity for northern Europe, Geophys. J. Int., 134, 102-144, doi:10.1046/j.1365246x.1998.00541.x, 1998b.

Lambeck, K., Purcell, A., Zhao, J., and Svensson, N.-O.: The Scandinavian Ice Sheet: from MIS 4 to the end of the Last Glacial Maximum, Boreas, 39, 410-435, doi:10.1111/j.15023885.2010.00140.x, 2010.

Lambeck, K., Purcell, A., and Dutton, A.: The anatomy of interglacial sea level: The relationship between sea levels and ice volumes during the Last Interglacial, Earth Planet. Sci. Lett., 4, 315316, doi:10.1016/j.epsl.2011.08.026, 2012.

Lidberg, M., Johansson, J. M., Scherneck, H.-G., and Milne, G. A.: Recent results based on continuous GPS observations of the GIA process in Fennoscandia from BIFROST, J. Geodyn., 50, 8-18, doi:10.1016/j.jog.2009.11.010, 2010.

Mitrovica, J. X., Tamisiea, M. E., Davis, J. L., and Milne, G. A.: Recent mass balance of polar ice sheets inferred from patterns of global sea-level change, Nature, 409, 1026-1029, doi:10.1038/35059054, 2001.

Pedoja, K., Husson, L., Regard, V., Cobbold, P. R., Ostanciaux, E., Johnson, M. E., Kershaw, S., Saillard, M., Martinod, J., Furgerot, L., Weill, P., and Delcaillau, B.: Relative sea-level fall since the last interglacial stage: Are coasts uplifting worldwide? Earth Sci. Rev., 108, 1-15, doi:10.1016/j.earscirev.2011.05.002, 2011.

Peltier, W. R.: Ice age paleotopography, Science, 265, 195-201, doi:10.1126/science.265.5169.195, 1994.

Peltier, W. R.: Global glacial isostasy and the surface of the ice-age Earth: the ICE-5G(VM2) model and GRACE. Annu. Rev. Earth Planet. Sci., 32, 111-149, doi:10.1146/annurev.earth.32.082503.144359, 2004.

Siddall, M. and Milne, G. A.: Understanding sea-level change is impossible without both insights from paleo studies and working across disciplines, Earth Planet. Sci. Lett., 315-316, 2-3, doi:10.1016/j.epsl.2011.10.023, 2012.
Simon, K. M., James, T. S., Dyke, A., and Forbes, D. L. Refining Glacial Isostatic Adjustment Models in Northern Canada: Implications for Ice Sheet History, Sea-Level Change, and Land Emergence Along the West Coast of Hudson Bay, AGU Fall Meeting Abstracts, G23B-04, 2011.

Steffen, H. and Kaufmann, G.: Glacial isostatic adjustment of Scandinavia and northwestern Europe and the radial viscosity structure of the Earth's mantle, Geophys. J. Int., 163, 801-812, doi:10.1111/j.1365-246X.2005.02740.x, 2005.

Steffen, H. and Wu, P.: Glacial isostatic adjustment in Fennoscandia - A review of data and modeling, J. Geodyn., 52, 169-204, doi:10.1016/j.jog.2011.03.002, 2011.

Steffen, H., Wu, P., and Wang, H.: Optimal locations for absolute gravity measurements and sensitivity of GRACE observations for constraining glacial isostatic adjustment on the northern hemisphere, Geophys. J. Int., 190, 1483-1494, doi:10.1111/j.1365-246X.2012.05563.x, 2012.

Törnqvist, T. E. and Hijma, M. P.: Links between early Holocene ice-sheet decay, sea-level rise and abrupt climate change. Nat. Geosci., 5, 601-606, doi:10.1038/ngeo1536, 2012.

Tushingham, A. M. and Peltier, W. R.: Validation of the ICE-3G model of Würm-Wisconsin deglaciation using a global data base of relative sea level histories, J. Geophys. Res., 97, 3285-3304, doi:10.1029/91JB02176, 1992.

Tushingham, A. M. and Peltier, W. R.: Implications of the Radiocarbon Timescale for Ice-Sheet Chronology and Sea-Level Change, Quat. Res., 39, 125-129, doi:10.1006/qres.1993.1015, 1993.

van de Plassche, O.: Sea-Level Research: A Manual for the Collection and Evaluation of Data, GeoBooks, Norwich, 1986.

Vink, A., Steffen, H., Reinhardt L., and Kaufmann, G.: Holocene relative sea-level change, isostatic subsidence and the radial viscosity structure of the mantle of north-western Europe (Belgium, the Netherlands, Germany, southern North Sea), Quat. Sci. Rev., 26, 3249-3275, doi:10.1016/j.quascirev.2007.07.014, 2007.

Wang, H. S., Wu, P., and van der Wal, W.: Using postglacial sea level, crustal velocities and gravity-rate-of-change to constrain the influence of thermal effects on mantle lateral heterogeneities, J. Geodyn., 46, 104-117, doi:10.1016/j.jog.2008.03.003, 2008.

Wessel, P. and Smith, W. H. F.: New, improved version of generic mapping tools released, EOS, 79, 579, doi:10.1029/98EO00426, 1998.

Wu, P., Wang, H. S., and Schotman, H.: Postglacial induced surface motions, sea levels and geoid rates on a spherical, selfgravitating laterally heterogeneous earth, J. Geodyn., 39, 127142, doi:10.1016/j.jog.2004.08.006, 2005.

Wu, P., Steffen, H., and Wang, H. S.: Optimal locations for GPS measurements in North America and northern Europe for constraining Glacial Isostatic Adjustment, Geophys. J. Int., 181, 653-664, doi:10.1111/j.1365-246X.2010.04545.x, 2010.

Wu, P., Wang, H., and Steffen, H.: The role of thermal effect on mantle seismic anomalies under Laurentia and Fennoscandia from observations of Glacial Isostatic Adjustment, Geophys. J. Int., 192, 7-17, doi:10.1093/gji/ggs009, 2013. 